\title{
A Financial, Environmental and Social Evaluation of Domestic Water Management Options in the West Bank, Palestine
}

\author{
Dima W. Nazer • Maarten A. Siebel • Pieter Van der Zaag • \\ Ziad Mimi • Huub J. Gijzen
}

Received: 23 October 2009 / Accepted: 6 May 2010 /

Published online: 28 May 2010

(C) The Author(s) 2010. This article is published with open access at Springerlink.com

\begin{abstract}
Water is one of the most valuable natural resources in the West Bank, Palestine. Due to its limited availability, it is a resource that needs particular protection. Although agriculture consumes most of the water (70\%) in the West Bank, the domestic water supply is strategically not less important. It is the aim of this study to evaluate domestic water management options suitable for Palestinian conditions that contribute to achieving water sufficiency in the domestic water use in the house of tomorrow. A number of options were evaluated economically, environmentally and socially using the concept of life cycle impact assessment (LCIA). Results of the study showed that by introducing a combination of domestic water management options, a substantial decrease in the water consumption of more than $50 \%$ can be
\end{abstract}

D. W. Nazer $(\varangle)$

Palestine Technical College-Arroub, P.O. Box 606, Hebron, West Bank, Palestine

e-mail: nazerdima@hotmail.com

M. A. Siebel · P. Van der Zaag

UNESCO-IHE Institute for Water Education, Delft, The Netherlands

M. A. Siebel

e-mail: m.siebel@unesco-ihe.org

P. Van der Zaag

e-mail: p.vanderzaag@unesco-ihe.org

P. Van der Zaag

Water Resources Section, Delft University of Technology, Delft, The Netherlands

Z. Mimi

Institute of Environmental and Water Studies, Birzeit University, Ramallah, Palestine e-mail: zmimi@birzeit.edu

H. J. Gijzen

UNESCO Jakarta Office, Regional Bureau for Science for Asia and Pacific,

Jakarta, Indonesia

e-mail: h.gijzen@unesco.org 
achieved, thereby reducing the pressure on the scarce water resources. The annual environmental impact of the in-house water use can be reduced in the range of $8 \%$, when using low-flow shower head to $38 \%$ when using rainwater harvesting systems. Some of the options (faucet aerators, low-flow shower heads and dual flush toilets) were found to be financially attractive with a pay back period of less than their expected lives, others (rainwater harvesting, graywater reuse and dry toilets) were found to be financially unattractive because of the high investment. In the social context, it was found that introducing such options can improve the quality of life of those not having enough water. There is already a popular willingness to take part in water conservation in the domestic sector in the West Bank. The strongest driving force for using water conservation measures is the awareness that water is a scarce resource. It was concluded that, theoretically, the house of tomorrow can be largely independent in terms of water and sanitation. Education and awareness campaigns in the context of water management with a focus on non-traditional options are key to achieve such a house.

Keywords Environmental impact • Financial assessment • House-hold water management • Social impact assessment • Water reuse • Water scarcity $\cdot$ West Bank

\section{Introduction}

Continuing growth in population and development increases the pressure on water resources all over the world. As a consequence, the number of countries dealing with water scarcity is increasing. This growing water scarcity can clearly be seen in the Middle Eastern region including the West Bank in Palestine.

The political situation in the area makes the water issue in the West Bank complicated. Since 1967, when Israel occupied the West Bank, the water resources have been controlled by Israeli military orders which have severely restricted Palestinian use. The Palestinians are denied access to River Jordan water. Moreover, there is currently an inequitable distribution of the water resources in the area between Palestinians and Israelis; the per capita water use, for all purposes, of the Israelis is six times that of the Palestinians. In addition, the future water allocation is even more problematic (Nazer 2009). The per capita water availability in 2005 in the West Bank was $80 \mathrm{~m}^{3} /$ year and this number is expected to decrease to $45 \mathrm{~m}^{3} /$ year by the year 2025 (Nazer et al. 2008). This number is very low by any standard.

Water scarcity is not only driven by politics it is also exacerbated by the way water is used in the West Bank. Water is used and disposed of without considering further uses. In most cases the used-water, or what is called wastewater, is discharged into the wadis (dry riverbeds) without any type of treatment, reducing water quality and, therefore, reducing the availability of good quality water (Nazer 2009). This so-called use and dispose approach to water needs urgent reconsideration so as to arrive at a sustainable water use where wastewater is viewed as a resource, ready to be used again. In the so-called use-treat-reuse approach, both the water use and the environmental impact of domestic water use are significantly reduced. Waste is treated on site and benefits may be derived from what is considered waste by reusing it or recovering some of its components. In line with this thinking, in the remainder 
of this paper wastewater is referred to as "used-water". A large range of options exist to achieve significant reduction in overall water use, making each drop of water more productive (Cunningham and Saigo 1999; Matsui et al. 2001; Rosegrant et al. 2002; Nazer et al. 2008).

The objective of this study is twofold:

1. To evaluate the environmental, financial and social impacts of potential domestic water management options using Life Cycle Impact Assessment (LCIA). These options can be alternatives for water saving or conservation, development of new resources and water reuse.

2. To propose a water use scheme for the house of tomorrow, in line with the use-treat-reuse approach. In this study the house of tomorrow refers to separate houses, housing complexes or buildings.

\section{Background}

\subsection{Sustainable Development in Domestic Water Use}

Sustainable development was defined by the United Nations' World Commission on Environment and Development as "development that meets the needs of the present without compromising the ability of future generations to meet their needs" (WCED 1987). Sustainability has environmental, financial and social dimensions, that is, for an activity to be sustainable it should be ecologically sound, socially acceptable and economically viable (Hauschild et al. 2005).

In the West Bank industrial water use is small relative to other water uses, but exact numbers are not available. Industrial consumption is usually included in the domestic water consumption, and together industrial and domestic comprise $30 \%$ of the total water use (Nazer 2009; PWA 2005, personal communication). Although the domestic and industrial sectors use far less water than agriculture (30\% versus $70 \%)$, water demand in the domestic sector is growing rapidly. Water sustainability could be achieved through implementing water saving practices and using newly developed water management approaches. Some examples are listed, these examples can be categorized as:

1. Rainwater harvesting systems (RWHS); in these systems rainwater is collected from roofs or rocks and stored in cisterns to be used afterwards thus providing an alternative water resource (Baguma et al. 2010)

2. Demand management alternatives which consist of

Water saving alternatives

- Faucet aerators (FA) and low-flow shower head (LFSH): these devices restrict the amount of water going through the faucet or shower heads, but add air so the flow of water appears the same (Mayer et al. 2004).

- Dual flush toilets (DFT): these are toilets that use less water than conventional toilets and have two volumes of flushes (Mayer et al. 2004).

- Dry toilets (DT): toilets that do not use water or use a small amount of water. Some of these toilets separate urine from faeces (Matsui et al. 2001). These toilets have dual advantage, less water use and less chances of water 
resources destruction due to pollution. Moreover, these are considered options for resource recovery as the waste can be used for energy and fertilizer production.

- Leakage prevention (LP): this refers to fixing leaking appliances.

Water reuse alternatives

- Gray-water reuse systems (GWRS): gray-water is defined as untreated, used household water from showers, bathrooms, wash basins and washing machines (Bennett 1995).

\subsection{Cleaner Production}

Cleaner Production is commonly defined as "the continuous application of an integrated preventive environmental strategy applied to processes, products and services to increase overall efficiency and reduce risks to humans and the environment" (UNEP 1999). Although this definition needs a slight adaptation in the context of urban water, the essential elements of Cleaner Production, i.e. the proper choice of materials, process efficiency, reuse and recycling of materials and least impact treatment with recovery of resources, remain valid (Gijzen 2001; Siebel and Gijzen 2002). It could be said that, Cleaner Production thinking has penetrated the way we deal with water: 130 to 500 l/cap/day of drinking water are used, but less than $10 \mathrm{l}$ are actually needed for drinking and food preparation. The difference is largely used to flush away waste (Gijzen 1998; Siebel and Gijzen 2002).

\subsection{Life Cycle Impact Assessment (LCIA)}

Life cycle impact assessment (LCIA) is the process of quantifying the impacts of products, processes and services over the entire period of their life cycle. In carrying out a LCIA, all major impacts should be taken into account (UNEP 1996; EEA 1997). LCIA was first developed in the seventies and has been further developed and become the standard when comparing alternatives. More recently a similar approach has been used in the financial area to quantify financial impacts of products, processes and services (Barrios et al. 2008). Moreover, developments in LCIA are moving towards the inclusion of the social dimension (Udo de Haes et al. 2004; Hauschild et al. 2005; Siebel et al. 2007). A combination of the three dimensions of sustainable development (environmental, financial and social) results in an attractive approach, but at the same time poses the risk of impossible data and resource requirements (Udo de Haes et al. 2004).

\subsubsection{Environmental Life Cycle Impact Assessment (E-LCIA)}

The production or use of a product or the rendering of a service involves a number of steps. These steps include extracting and converting resources, manufacturing products, providing infrastructure for transportation and manufacturing, using the product or service, and recycling or disposing of the product that no longer serves its purpose. These steps consume resources, produce pollution and, hence, cause environmental impacts. After an inventory phase in which data about all types of substances that affect the environmental impact is collected, the impacts are categorized and assessed so as to be expressed in a single quantity. In this study, the 
environmental impact was assessed using the Eco-indicator 99 method (Goedkoop et al. 2000).

\subsubsection{Financial Life Cycle Impact Assessment (F-LCIA)}

In analogy to E-LCIA, F-LCIA is defined as the process of quantifying the financial impacts of a product, process or service during all phases of its life cycle (production, operation and disposal). There are mainly three groups of financial elements that may play a role in F-LCIA:

1. One-time cost these relate to investment for the acquisition of land area, the construction of buildings, the purchasing of production or transport equipment and, at the end of the lifetime, the costs of disposal of facilities.

2. Recurrent costs these relate to operational costs such as cost of labor, of raw materials and energy, of operating equipment and of maintenance. In addition, revenues from the sale of products or services are recurrent costs.

3. Cost-related parameters these relate to interest, inflation and depreciation.

F-LCIA can be used to compare the life cycle costs of system alternatives serving the same purpose (Siebel et al. 2007). A cost comparison of alternatives can be done on the basis of a true financial comparison of alternatives taking into account all present and future costs. The present worth (PW) is one such method which relates the cost of any activity at a certain time to the cost at another time given certain values for discount rate (Philippatos and Sihler 1991; Blank and Tarquin 2005). The PW of costs and benefits can be calculated according to Eq. 1.

$$
P W=A\left[\frac{(1+k)^{n}-1}{k(1+k)^{n}}\right]-I_{0}
$$

Where,

$P W$ : Present worth, is the monetary value at present or at time zero (US\$).

$A$ : Net annual benefits, (US\$/year)

$k$ : $\quad$ Discount rate,

$n: \quad$ Number of years (year).

$I_{0}$ : Investment in year zero (US\$).

\subsubsection{Social Life Cycle Impact Assessment (S-LCIA)}

In analogy to E-LCIA and F-LCIA, S-LCIA is defined as the process of quantifying the social impacts of a product, process or service over its life cycle. The production of a product, or the rendering of a service or the change therein, almost always has consequences not only in environmental and financial areas but may also affect those directly influenced by these changes, i.e. the consumers/users or those involved in the production of the products or the provisions of the services (Siebel et al. 2007). For example, as a result of a technological innovation, relatively low quality jobs may be replaced by a few relatively high quality jobs causing unemployment for many. It can be argued that a decrease in the availability of water may result in a decrease in the quality of health or may strain social (family) relations. Therefore, the level of happiness of those involved may be affected. On the other hand, water sufficiency will positively impact upon the quality of physical and social health and, therefore, increase the level of happiness. 
In conventional development theory, "happiness" equals money and prosperity. It was measured by gross national product (GNP). In 1972, Jigme Singye Wangchuch, the newly crowned king of the Himalayan Bhutan Kingdom, created the concept of gross national happiness $(\mathrm{GNH})$ to measure prosperity rather than GNP. The king maintains that the economic growth does not necessarily lead to contentment, and instead focuses on the four pillars of GNH: economic self-reliance, a pristine environment, the preservation and promotion of Bhutan's culture and good governance in the form of democracy (Ezechieli 2003; Bandyopadhyay 2005).

"Happiness" as a unit of social impact was first used by Hofstetter et al. (2006) who listed an extensive number of happiness enhancers and gave each a certain weight. Layard (2005) stated that happiness is a feeling that varies over time throughout our life. The average happiness is determined by one's pattern of activities, one's nature and attitudes and by key features of one's situation, social relationship, health, worries, etc. There are countless sources of happiness and countless sources of pain and misery. Layard (2005) stated that there are seven enhancers of happiness i.e. family relationships, financial situation, work, community and friends, health, personal freedom and personal values. Similarly, Siebel et al. (2007) proposed five categories of happiness, job quality, quality of physical health, quality of social health, earthly possessions and various.

Siebel et al. (2007) developed a simple approach to quantify the social impact of societal or industrial activities. The approach is based on the assumption that each person starts out with a given value of happiness, expressed as Socio-points in S-LCIA (in analogy with Eco-points for E-LCIA and Euro-points for F-LCIA). Over the years, this initial happiness value will change as a result of concrete physical or emotional experiences such as a painful accident, not passing an important exam, a prison sentence, or from less identifiable influences such as having been born into a happy family, having had a bad youth or having a born physical handicap. Some of these experiences will reduce the initial value of happiness, others will increase it. By categorizing the various social impacts into the various happiness categories, and by equating each social impact with the maximum value in that category, the happiness of people can be quantified or the change in happiness of people can be assessed when determining the happiness value before and after the change. By determining the happiness values various times before and after a specific social change, the short and long-term impact of a certain social change can be determined.

\section{Materials and Methods}

\subsection{Research Approach}

An overview was made of potential domestic water management options on the basis of their financial, environmental and social impacts. One option focuses on developing a new water resource, i.e. rainwater harvesting system (RWHS) and one focuses on water reuse, i.e. grey-water reuse system (GWRS). Moreover, four indoor water saving options were evaluated; two were related to the toilet as the largest indoor water consumer in the West Bank (34\%), i.e. the dual flush toilet (DFT) and the dry toilets (DT). Also the low flow shower head (LFSH) was chosen to cover the bath and shower water consumption (22\%) and the faucet aerators (FA) was chosen to cover the bathroom sink and the kitchen with $14 \%$ and $13 \%$ respectively of the 
indoor water use. Remaining consumption (17\%; laundry, cooking and drinking and house cleaning) was relatively small (Nazer et al. 2007).

The comparison of the options was made on the basis of evaluating the expected change (increase or decrease) in the environmental, financial and social impacts due to the implementation of these options. The do-nothing alternative was the reference for calculating the change. An inventory analysis was carried out to determine the changes associated with the implementation of each option, i.e. water use, used-water production and energy consumption. The calculations were based on the per capita water consumption in the West Bank distributed over the different indoor water consumption points (toilet, kitchen, bath, laundry etc) (Nazer et al. 2007).

\subsection{Life Cycle Impact Assessment}

LCIA was chosen to evaluate the change (increase or decrease) in the environmental, financial and social impacts as a result of the implementation of the studied options. Although LCIA involves the three phases of the life cycle, i.e. production (manufacturing/construction and installation), operation and disposal/demolition, the analysis in this study is made for the production and operation phases only because systematic investigation about disposal and demolition of house-hold sanitary systems does not exist in the West Bank.

\subsubsection{Environmental Life Cycle Impact Assessment (E-LCIA)}

The following steps were carried out:

1. The environmental impact of producing (manufacturing/constructing and installing) each option was determined using the Eco-indicator 99 database (Goedkoop et al. 2000) in which the environmental impact was given in ecopoint/unit weight of material. For each option, the materials used in the production of that option were investigated in terms of type and weight, and then the environmental impact was calculated.

2. On the basis of the inventory analysis of implementing the water management options, the changes in pollutant emissions to air, water and soil resulting from the changes in water use, used-water production and energy consumption were determined. According to these emissions the change in environmental impact was determined.

\subsubsection{Financial Life Cycle Impact Assessment}

In order to evaluate the financial costs of each water management option the following steps were carried out:

1. Determination of the investment (US\$).

2. Determination of the annual operational costs (US\$/year).

3. Determination of the annual savings in operational costs (US\$/year).

4. Determination of the present worth of the costs and benefits (US $\$ /$ year).

Calculations were carried out for a period of 10 years. Discount rate and operation and maintenance were estimated at 5\% per year (CIA 2009; Hutton and Bartram 2008). Discount rate is the average discount rate of Israel and Jordan provided by CIA (2009) because a discount rate for Palestine is not available. 


\subsubsection{Social Life Cycle Impact Assessment}

To approach the social aspects of the various water management options in this study, the impact of these options on the level of happiness of people using or willing to use these options was assessed. A questionnaire was prepared for this purpose; the questionnaire contained both closed and open questions. The closed (yes/no) questions were about the willingness to use and to pay for the different options, while the open questions were about the reasons behind accepting or rejecting certain options. After an explanation of each option, the respondents were asked if they were willing to use an option and the reasons behind their willingness to use or not to use it. The respondents were also asked if they were willing to pay for the option in question and why. The respondents could give one or more reasons.

Three groups with a total of 244 adults were involved in the study. The first group (92 participants) was chosen from general users of water from different segments of society: students, employees, house-wives. These people were approached through workshops in different localities in the West Bank. The workshops began with an introduction about the West Bank water resources and the water scarcity in the area. The in-house water consumption pattern was then explained followed by an overview of potential options available for reducing in-house water use and their associated financial and environmental costs and benefits. Finally the participants were asked to fill out the questionnaire. The second group (120 participants) filled out the questionnaire with the help of university students who first explained the options. The third group (32 participants) was formed by professionals in the water sector.

The average initial value of happiness of a Palestinian in the West Bank was set at 500 Socio (happiness)-points. This initial value is expected to change as a result of life experiences. In this study the difference between living in a country characterized by a situation of serious and increasingly serious water stress vs. living in a country in which this situation of water stress is reduced as a result of measures meant to reduce water consumption and, therefore, water stress, was quantified and related to the happiness of the people. The questionnaire was meant to quantify the change in the feelings of people relative to the situation before and after taking appropriate measures to improve water availability (i.e. reduce water stress). In doing so, it was assumed that if a person is willing to use an option, then using this option increases the initial value of happiness of this person by a value of $a$ socio-points because of the perception of contributing to a good cause, a better life, etc. Furthermore, if that person is willing to pay for that specific option, the value of happiness of the person increases further by another value of $b$ socio-points. On the other hand, if a person is rejecting (equal to: not willing to use) the option, the happiness level of this person is expected to drop by $a$ socio-points. The use of a particular option could, for example, become enforced as part of a government measures to reduce water stress. If this person is not willing to pay for this specific option, it means that paying for that option is expected to further decrease the level of his happiness by $b$ socio-points.

In a group of people, the overall level of happiness is influenced by the level of variation in happiness of this group. The happiness level may increase for some participants, may decrease for others, or remain the same. Accordingly, the change in happiness of a group of people is the increase in happiness of some minus the decrease in happiness of others. Therefore, the change of happiness for a group 
of people, or the social impact as it will be called in the rest of the paper, can be calculated according to Eq. 2.

$$
\Delta S=a \alpha_{u}+b \beta_{p}-a \alpha_{n u}-b \beta_{n p}
$$

where

$\Delta S$ : Change in the level of happiness or the social impact of a group (socio-points), $\alpha_{u}$ : Willingness to use, given as the fraction of respondents willing to use the option (range: $0-1$ ),

$\beta_{p}$ : Willingness to pay, given as the fraction of respondents willing to pay for the option (range: $0-1$ ),

$\alpha_{n u}$ : The fraction of respondents not willing to use the option (range: $0-1$ ),

$\beta_{n p}$ : The fraction of respondents not willing to pay for the option (range: $0-1$ ),

$a, b$ : Constants describing the effect of not having water on the person's level of happiness.

Given that the respondents were asked to express their willingness to use or pay for (yes/no answers), this implies that:

$$
\begin{aligned}
\alpha_{n u} & =1-\alpha_{u} \text { and } \beta_{n p}=1-\beta_{p} . \text { Therefore Eq. } 2 \text { becomes } \\
\Delta S & =2 a \alpha_{u}+2 b \beta_{p}-(a+b)
\end{aligned}
$$

In the case of a situation of serious water stress, it is assumed that willingness to pay approaches the willingness to use a certain option. In that case $a$ and $b$ are equal and the Eq. 3 simplifies to

$$
\Delta S=2 a\left(\alpha_{u}+\beta_{p}-1\right)
$$

In order to determine the values of $a$ and $b$, a group of 52 people, randomly chosen from the telephone book of the residents of West Bank, were asked how much their happiness would be affected if they wanted to do something that needed water such as taking a shower, washing, cleaning, etc. only to find out that there would be no water to do so. They were asked to rate the ups or downs of their happiness level on a scale of $0-100$. The response of the respondents suggested that the level of happiness will decrease by $70 \%$. The situation of not having water when needed may affect two of the big seven enhancers of happiness proposed by Layard (2005), i.e. health and family relationships. Assuming that each of the big seven enhancers has an equal effect on happiness, then not having water will affect $2 / 7$ th of the total decrease in happiness $(70 \%)$. Therefore, the initial level of happiness will be decreased by $(2 / 7$ of $70 \%)=20 \%$. So a value of $100(20 \%$ of 500 the initial average) sociopoints for the total decrease or increase in the level of happiness ( $a$ plus $b$ ) could be reasonable. Assuming that $a$ and $b$ are equal, then each of them will take a value of 50 socio-points.

\subsection{List of Assumptions Regarding Water Management Options}

There are a variety of ways to produce the chosen water management options which vary significantly with regard to the materials used for producing or constructing them, cost, environmental impact etc. For example, a rainwater harvesting reservoir could be made of plastic, concrete or any other material according to which the cost 
and the environmental impact may vary significantly. Therefore, assumptions were made in this study for the sake of the calculations:

1. The average family size in the West Bank is 6 (PCBS 2007).

2. The water consumption pattern is according to Nazer et al. (2007) study. In this study, indoor water consumption was measured with the help of school students. The results of the study indicate that a person in the West Bank on average uses $38 \mathrm{l} / \mathrm{d}$. The water consumption in the bathroom (toilet flushing, bath and shower and sink) accounts for $70 \%$ of all indoor water use. The heaviest user is the toilet, accounting for $34 \%$. In contrast cooking and drinking together account for the smallest fraction, $4 \%$, of the total water use.

3. It is assumed that dry toilets do not use any water, are made of polypropylene and have a total weight of $13 \mathrm{~kg}$. Calculation of the compost for dry toilet is based on a production of $12 \mathrm{~kg} /$ person/year (Matsui et al. 2001). Price of compost was estimated on the basis of local market at \$US $0.3 / \mathrm{kg}$ of compost (personal communication).

4. A dual flush toilet uses one full flush/cap/day (6 1) and two reduced flushes/ cap/day (3 1) (EPA 1995). It is made of ceramics with a total weight of $35 \mathrm{~kg}$.

5. A gray-water reuse system uses the water used in the sink, bath, shower and laundry. It consists of a plastic reservoir and plastic piping system.

6. A Low-flow shower head saves about $40 \%$ of the water used by traditional shower heads (EPA 1995). They are made of plastic with a weight of $0.15 \mathrm{~kg}$.

7. Faucet aerators can reduce the water used in the faucets by $60 \%$ (EPA 1995). They are made of plastics.

8. Leakage in the West Bank accounts for some $30 \%-40 \%$ of the consumption (PECDAR 2001). Due to system improvements and increased awareness of water scarcity, leakage prevention saves $10 \%$ of the total consumption.

9. Rainwater harvesting, these are reinforced concrete reservoirs with an average volume of the cistern of $80 \mathrm{~m}^{3}$ (MOPIC 1998). The size of the cistern was crosschecked using the methodology developed by Van der Zaag (2000); the idea is to calculate the size of a rain water harvesting storage tank that can satisfy a household for a given satisfactory level (30-90\%).

\section{Results and Discussion}

\subsection{Inventory of Change in Resource Use}

Table 1 presents the annual resource (water and energy) use and the used-water (wastewater) production before implementing (do-nothing alternative) and after implementing the different water management options together with the change in resource use.

\subsection{Environmental Impact}

Table 2 presents the environmental impact of the production (manufacturing/ construction) and the annual reduction in the environmental impact due to the implementation of the different water management options as well as the annual net reduction in the environmental impact. Although the environmental impact of 


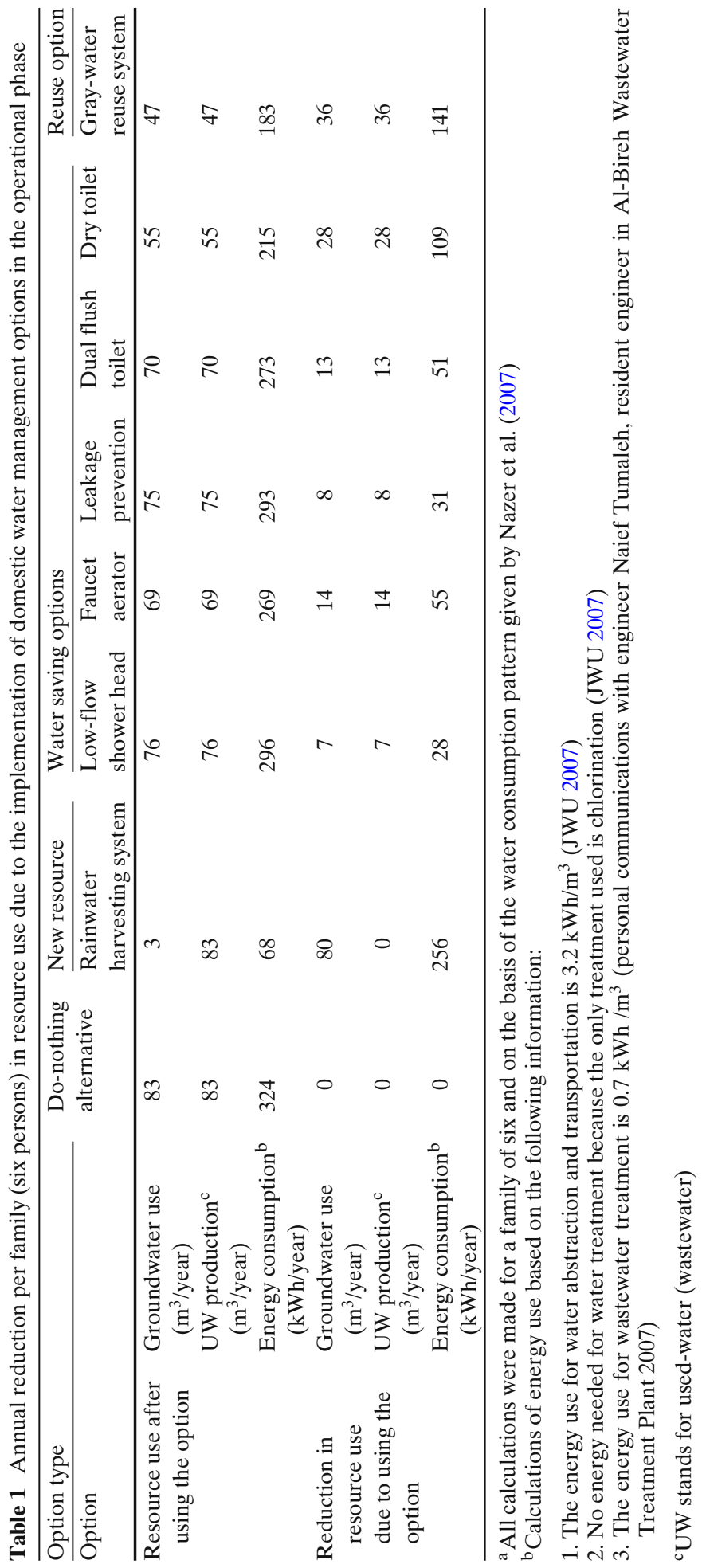




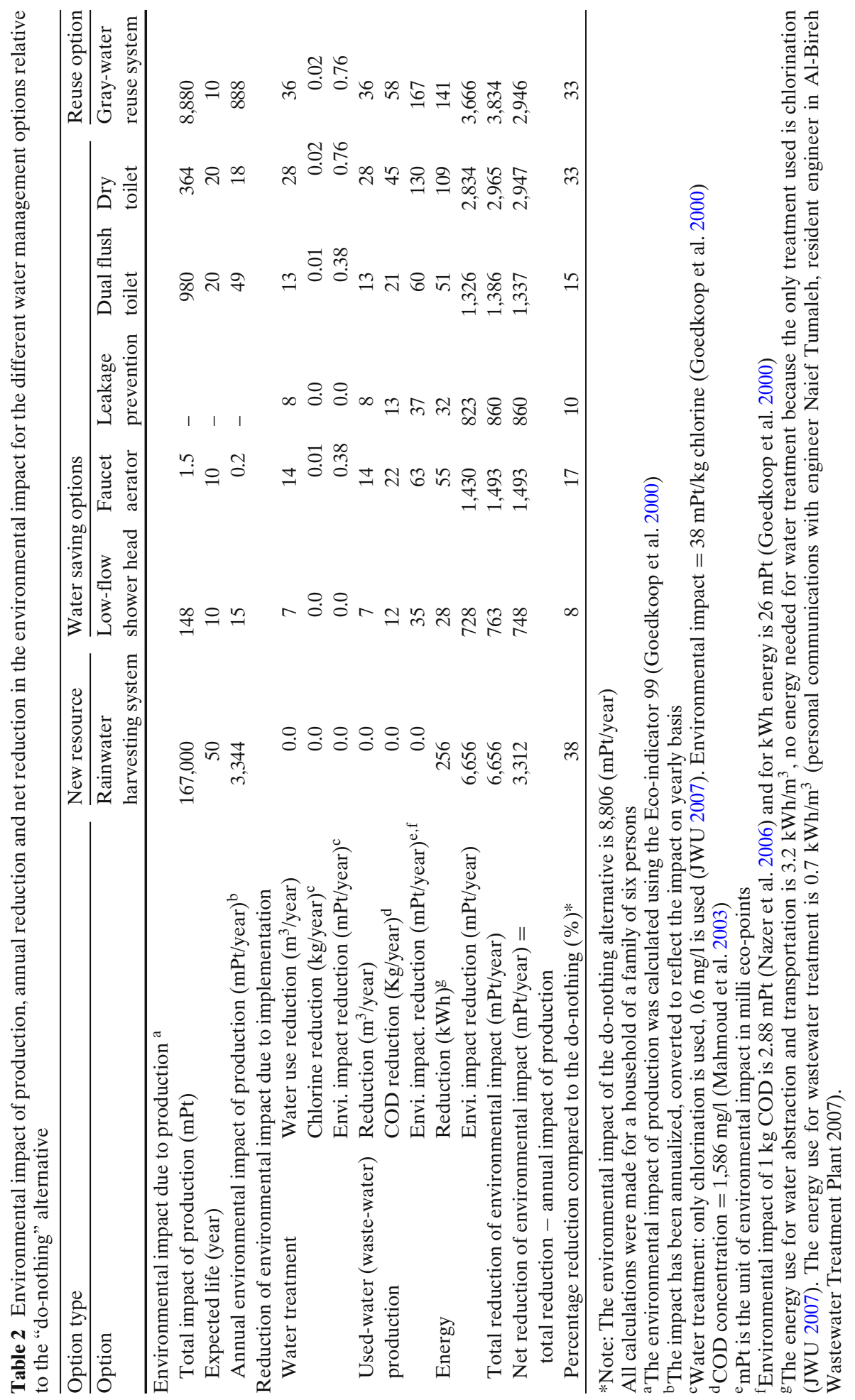


constructing the rain water harvesting system is very high relative to other options, it is the most environmentally sound option with respect to the net reduction in the environmental impact, followed by the dry toilet and gray-water reuse systems. In the case of the dry toilet, the reduction in the environmental impact, due to the use of compost produced in the toilet as a substitute fertilizer, was not included in the calculation. Nevertheless, this will increase the environmental benefits. It can be seen that the largest fraction of environmental impact reduction is from energy reduction.

\subsection{Financial Impact}

Initial investments for the management options vary significantly between options according to type, manufacturer and place of installation. For example, costs of gray-water systems vary from simple inexpensive diverters which cost less than $\$ 200$ a piece to complex treatment, storage and irrigation systems that cost several thousands of dollars (PLANETARK 2007). Cost calculations in this study were based on investment costs given by the specified reference in Table 3.

From Table 3 it can be seen that the present worth $(P W)$ of the rainwater harvesting gray-water reuse, and dry toilets is negative which means that these are financially unattractive. This can be explained by the high investment needed for these alternatives. However, the social benefits including the gain in productive time resulting from improved health, the time saving associated with better access to water and sanitation, and economic gains associated with saved lives were not included in the calculations; Hutton et al. (2007) estimated the average rate of return of these benefits at a global average of US\$ 8.1 per dollar invested for combined water supply and sanitation. It should be noted that the calculations in this study were based on the existing prices of water and energy. These are expected to rise in the future due to the increasing water scarcity with a consequent increase in the benefits of any water saving system.

The faucet aerator was found to be the most financially feasible on annual basis followed by, low flow-toilet and low-flow shower heads (Table 3). The pay back period for faucet aerators, low-flow shower heads, dual flush toilets options, was less than their expected life. In this context Mayer et al. $(2003,2004)$ said that an analysis of cost and benefit for installing low flow-toilets and low-flow shower heads showed that these products pay for them selves in water and sewer cost savings. The payback time for installing low-flow toilets (from savings on water and wastewater charges) was under 2 year, for a showerhead was 1.6 years and for a faucet aerator was under 1 year.

\subsection{Social Impact}

Figure 1 presents the expected change in the level of happiness of people as a result of implementing the different options for the three groups of people investigated. Table 4 presents the detailed results of the group who did not attend the workshops as an example. It can be seen that the most socially acceptable water management options are leakage prevention (LP) and rainwater harvesting (RWHS). The dry toilet (DT) is the least socially acceptable.

Results of the study showed that attending the workshops succeeded in improving the participants' awareness about water conservation options, including such 


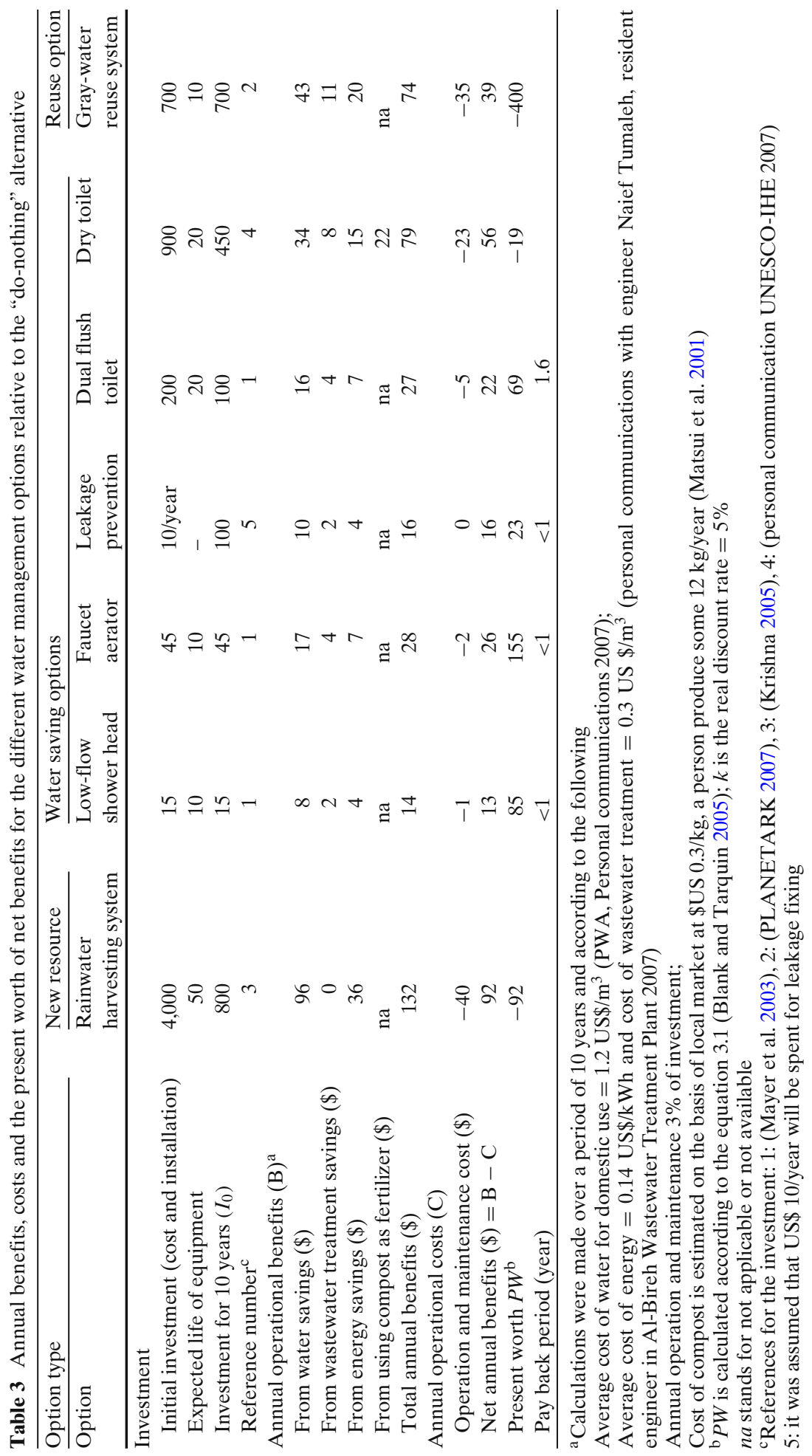




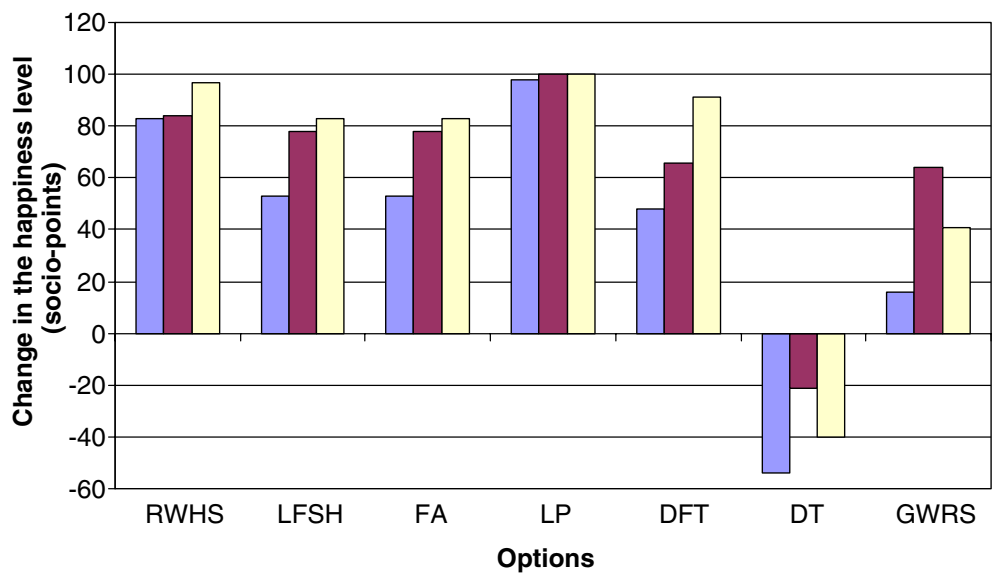

$\square$ Non-workshop attendees $\mathrm{N}=120 \square$ Workshop attendees $\mathrm{N}=92 \square$ Professionals $\mathrm{N}=32$

Fig. 1 Expected change in the level of happiness as a result of implementing water management options among the sampled societal groups

non-traditional options as the dry toilets. For example, the social impact of using dry toilets was minus 54 socio-points in the non-workshop attendees (participants who did not attend workshops); while the impact increased to minus 21 socio-points among the workshop attendees (participants who attended the workshops). Social impacts of gray-water reuse, dual flush toilets and faucet aerators also increased among the workshop attendees relative to the non-workshop attendees (Fig. 1). Hence, we can conclude that wider awareness raising programs such as a televised national debate or discussion could be very useful.

In order to explain statistically the relationship between the level of awareness and the willingness to use and pay for each option, or in other words to explain the difference in the change of happiness between the workshop attendees and the nonworkshop attendees, the chi-square test was used.

The calculated chi-square value for dry toilets and grey-water reuse systems exceeded the critical value 3.84 at $5 \%$ level of significance (Table 5) meaning that attending the workshops had a significant positive effect on the participants willingness to use and pay for the presented options. However, for rainwater harvesting systems and leakage prevention there was no significant difference between the two groups (Table 5). This can be explained by the fact that these options are wellknown and widely used in the West Bank. There was also a significant difference between the professionals and the group of the non-workshop attendees. The social impact was greater in the professionals' group. This can be explained by the fact that the professionals were well aware of these water management options because of their professional background in the water sector. However, the social impact of dry toilets and grey-water systems in the professionals group is less than the impact in the workshop attendees group. This may be because the professionals are educated with the idea that "water is plentifully available" and "all problems of water can easily be solved" (just like a medical doctor is raised with the concept of "treatment first"). Therefore, in the professionals' mind, tools that save water or eliminate the use of 


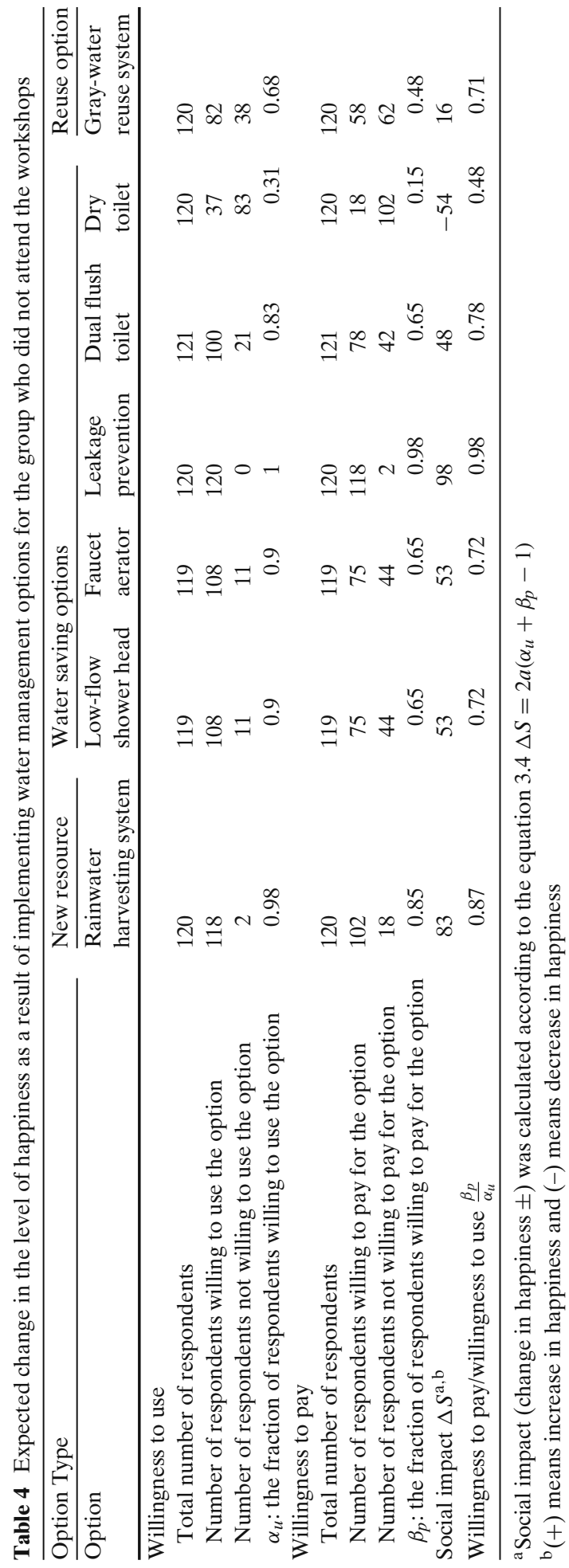


Table 5 The calculated and critical value of chi-square between the workshop attendees group and the non-workshop attendees group for the different water management options

\begin{tabular}{lllllllll}
\hline Option & $\begin{array}{l}\text { Rainwater } \\
\text { harvesting } \\
\text { system }\end{array}$ & $\begin{array}{l}\text { Low-flow } \\
\text { shower } \\
\text { head }\end{array}$ & $\begin{array}{l}\text { Faucet } \\
\text { aerator }\end{array}$ & $\begin{array}{l}\text { Leakage } \\
\text { prevention }\end{array}$ & $\begin{array}{l}\text { Dual } \\
\text { flush } \\
\text { toilet }\end{array}$ & $\begin{array}{l}\text { Dry } \\
\text { toilet }\end{array}$ & $\begin{array}{l}\text { Gray-water } \\
\text { reuse } \\
\text { system }\end{array}$ \\
\hline $\begin{array}{c}\text { Calculated } \\
\text { chi-square }\end{array}$ & $\begin{array}{c}\text { Willingness } \\
\text { to use } \\
\text { Willingness } \\
\text { to pay }\end{array}$ & 0.7 & 3.3 & 3.3 & 0.0 & 3.6 & 6.2 & 17.8 \\
& 0.04 & 8.2 & 8.2 & 1.3 & 2.1 & 5.3 & 10.1 \\
\hline
\end{tabular}

Note: Critical value of chi-square is 3.84 at $5 \%$ level of significance, a value $<3.84$ means no significant difference between the groups and a value $>3.84$ means there is a significant difference (Chase and Bown 1986)

water in clear cases of potential negative impact on the public health, are simply not done, these are outside their professional interest.

It can be concluded that making people aware of certain water management options, including such non-traditional options as the dry toilets, increases the willingness to use and pay for these options and, hence, the social impact (change in happiness level) due to using these options.

It was found that the willingness to pay for an option is less than the willingness to use that option, $\alpha_{u} \leq \beta_{p}$ and therefore $\frac{\beta_{p}}{\alpha_{u}} \leq 1$ (Table 4). However, the willingness to pay for the option is expected to increase with increasing importance of that option. For example, a person may be willing to use a rainwater harvesting system but may not be willing to pay for it if the availability of water is not a critical issue. But if water availability is a daily issue, that person's willingness to pay will approach his or her willingness to use. From Fig. 2, it can be seen that $\frac{\beta_{p}}{\alpha_{u}}$ for options considered important

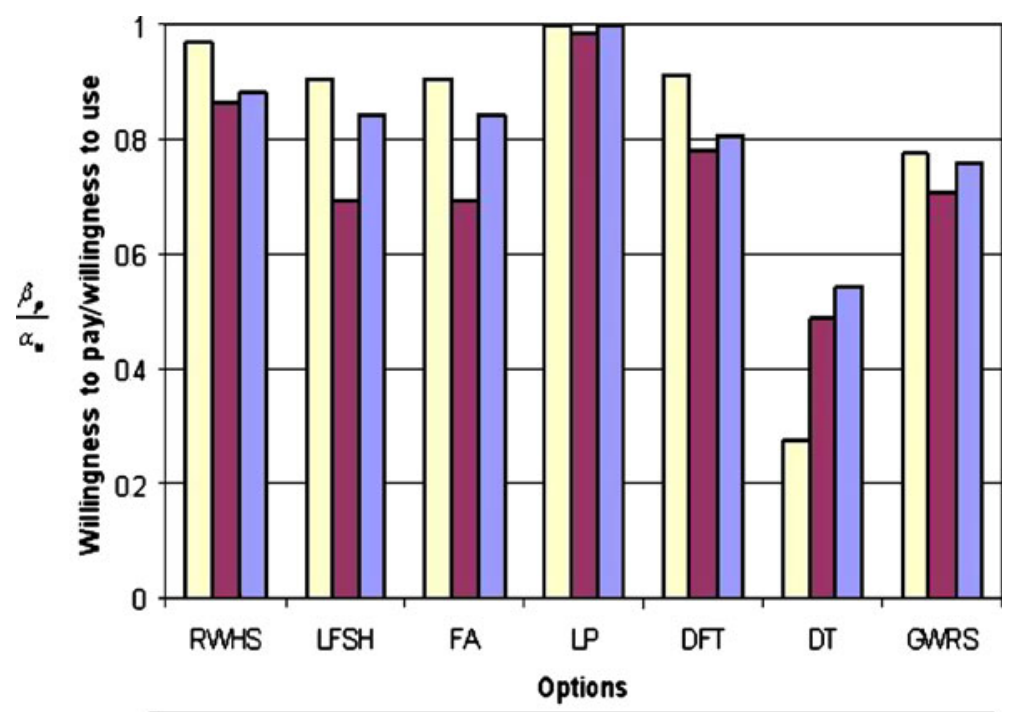

口Professionals $\square$ Non workshop atendees $\square$ Workshop atendees

Fig. 2 Willingness to pay/willingness to use, $\frac{\beta_{p}}{\alpha_{u}}$ for the different water management options 
such as leakage prevention is approaching 1 while that for options considered not important it is less than 1 . Therefore, efforts should be devoted towards increasing the awareness about the options which are considered of low importance.

\subsubsection{Reasons Behind Accepting or Rejecting Water Conservation Options}

The respondents of the three groups were asked about the reasons behind their willingness or un-willingness to use and to pay for the options.

Dry Toilets (DT) Participants who rejected DT explained their rejection for emotional, religious, public health and financial reasons amongst others. The emotional reason was the dominant: $48 \%$ of participants who reject these toilets said they just could not use these toilets. Public health concerns scored $30 \%$, religious concerns scored $18 \%$ of those not willing to use dry toilets (122). Those who said they were willing to use these toilets (90 respondents) did so for reasons of water saving $(63 \%)$, money saving (9\%), environmental saving (10\%) and other reasons $(18 \%)$.

Gray-Water Reuse Systems (GWRS) Participants who are willing to use GWRS (160 respondents) did so for reasons of water saving (49\%), money saving (6\%) and environmental saving (4\%). Public health concern was the most dominant reason for rejecting these systems (42\%) followed by the emotional reasons $(22 \%)$ of those not willing to use GWRS (46 respondents).

Dual Flush Toilets (DFT) Seventy-five percent of the participants who are not willing to use DFT (28 respondents) often felt that these devices are water wasting because of the large volume of water these devices use relative to the volume of hand flushing containers which they use. It is common in the area to use special containers to flush away the waste. The volume of these containers varies between 1 and 21 .

Rainwater Harvesting Systems (RWHS) Almost all workshop participants (98\%) were willing to use RWHS. These are considered as an alternative water resource to ensure water security when the piped water supply is cut off. Many participants suffer from losing access to water especially in summer when water is cut off for long periods. Some participants $(5 \%)$ said that it is the only water resource they have. Eighty-six percent of the workshop attendees and $85 \%$ of the non-workshop attendees have the willingness to pay for constructing a RWHS regardless of the high cost of these systems.

\subsection{Relating Environmental, Financial and Social Impacts}

Figure 3 shows a strong correlation between the environmental and financial benefits of the options during the operational phase: the coefficient of determination $R(0.89)$ is greater than the critical value of $R(0.708)$ for a level of significance of $(0.01)$ (Chase and Bown 1986). For one eco-point decrease in the environmental impact, there is an increase in profit of US\$ 107.

In contrast, it was found that the relationship between the social impact and both financial and environmental impacts is weak, the coefficients of determination $R, 0.52$ and 0.45 respectively, are less than the critical value of $R(0.708)$ for a level of significance of 0.01 (Chase and Bown 1986). This can be explained by the 
Fig. 3 Relationship between environmental impact and financial impact of the operational phase

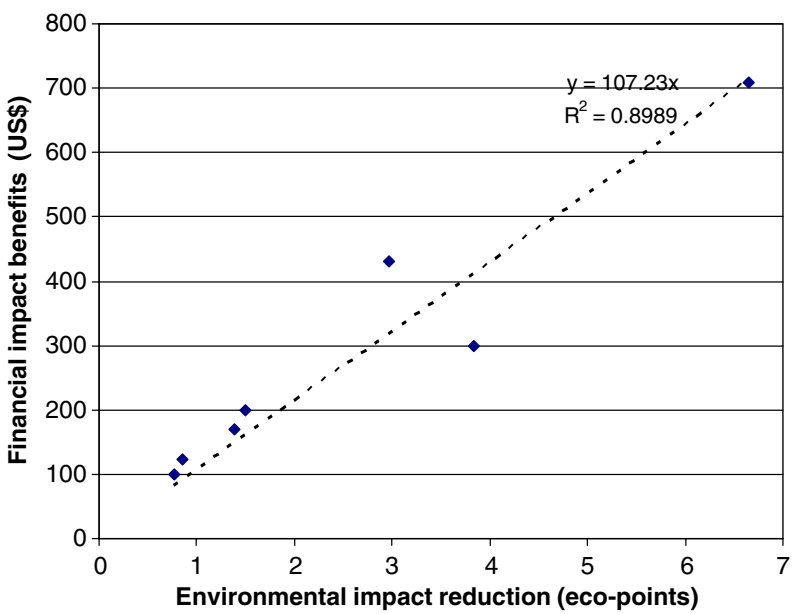

reasons behind the participants' willingness to use and pay for the options: the most motivating reason was water availability $(46 \%)$ rather than money saving $(6 \%)$ or environmental concerns (4\%). Moreover, the Palestinians have long ago adapted to water scarcity as a fact of life. This can be well illustrated by the fact that only $5 \%$ of the water use is withdrawn from existing groundwater resources and $43 \%$ is consumed from rain water through consuming rain-fed crops. In contrast, $52 \%$ of that water is imported in virtual form through imported goods (Nazer et al. 2008).

\subsection{The House of Tomorrow}

According to Nazer et al. (2007) the average in-house water consumption in the West Bank is $38 \pm 18 \mathrm{l} / \mathrm{cap} /$ day (Table 6). The large variation means that the inhouse water consumption varies considerably from place to place. Nevertheless, the numbers in Table 6 were used to show to what extent, even in conditions of limited water use, further water saving is feasible by combining different water management options in the so-called house of tomorrow. The implementation of these options can lead to a significant reduction in the per capita in-house water consumption from $38.1 \mathrm{l} / \mathrm{cap} /$ day to a minimum of $15.7 \mathrm{l} / \mathrm{cap} /$ day (Table 6 ). The combination proposed in this context is: dry toilet instead of water-based toilet, low-flow shower heads and faucet aerators, potentially resulting in over 50\% saving in water (Nazer et al. 2007). A gray-water reuse system can be installed through which the used-water can be reused for irrigating the garden, by doing so the outdoor consumption can be eliminated. According to the numbers presented in Table 6, a family of six will only need $34 \mathrm{~m}^{3} /$ year which could easily be harvested from rain water from a roof of $100 \mathrm{~m}^{2}$ area. In this context Zhang et al. (2010) stated that a reduction of some $32 \%$ of the water use can be achieved by gray-water reuse and rainwater harvesting allows for a reduction of $25 \%$. Ibrahim (2009) also found that rainwater harvesting can be a useful technique for providing safe water in water deficit areas in semi-arid regions.

In the proposed house of tomorrow a combination of six options was used. However, in some places some of these options may not be applicable. In such cases other combinations of two or three options could be used according to the specific 
Table 6 House-hold water consumption on a per capita basis without implementing water management options and expected per capita water consumption with implementation (Nazer et al. 2007)

\begin{tabular}{|c|c|c|c|c|c|}
\hline \multirow[t]{2}{*}{ Point of use } & & \multicolumn{2}{|c|}{$\begin{array}{l}\text { Per capita water } \\
\text { consumption without }\end{array}$} & \multicolumn{2}{|l|}{$\begin{array}{l}\text { Per capita water } \\
\text { consumption with }\end{array}$} \\
\hline & & $\begin{array}{l}\text { Average } \\
(1 / c / d)\end{array}$ & $\begin{array}{l}\text { Standard } \\
\text { deviation }\end{array}$ & $\begin{array}{l}\text { Proposed water } \\
\text { management option }\end{array}$ & $(\mathrm{l} / \mathrm{c} / \mathrm{d})$ \\
\hline \multirow[t]{3}{*}{ Bathroom } & Toilet flushing & 12.9 & 9.5 & $\begin{array}{c}\text { Dry toilet instead of } \\
\text { water based toilet }\end{array}$ & 0.0 \\
\hline & Sink & 5.3 & 4.1 & Faucet aerators & 2.1 \\
\hline & Bath and shower & 8.3 & 7.1 & Low-flow shower head & 5.0 \\
\hline \multirow[t]{2}{*}{ Kitchen } & Dish washing & 5.0 & 3.5 & Faucet aerators & 2.0 \\
\hline & Cooking and drinking & 1.6 & 1.5 & - & 1.6 \\
\hline \multirow[t]{2}{*}{ Cleaning } & Laundry & 3.0 & 3.1 & & 3.0 \\
\hline & House cleaning & 2.0 & 2.3 & - & 2.0 \\
\hline \multicolumn{2}{|c|}{ Total in-house } & 38.1 & 18.4 & & 15.7 \\
\hline \multicolumn{2}{|l|}{ Outdoor* } & 6.7 & & Gray-water use & 0.0 \\
\hline \multicolumn{2}{|l|}{ Total } & 44.8 & & & 15.7 \\
\hline
\end{tabular}

Note: outdoor water use was estimated at $15 \%$ of the total house use according to PWA (2005, personal communication)

Rain water reservoir with a minimum capacity of $40 \mathrm{~m}^{3}$ could be installed to guarantee the provision of the water needs of a family of 6 and a gray-water reuse system can also be installed which can make use of the 15.71 of the used-water in the house

conditions. For example in places where a dry toilet is not applicable, a low-flow toilet may be a substitution.

Using these options means that the four main principles of cleaner production are applied in the house of tomorrow, that is, the proper type of material (here water) is used, reuse of material is practiced, no mix of waste has been practiced and what is traditionally called waste is reused. By doing so less water is used, less used-water needs to be treated and fewer pollutants need to be removed.

In the above analysis, dry toilets play an important role, in spite of the fact that these are the least socially acceptable water conserving device of those investigated. However, it should be noticed that water availability predictions for the West Bank are dire. Less and less water will be available through the years to come leaving no other choice than to go for the most effective water conservations options. Timely planning and awareness raising are, therefore, vital ingredients in averting what is bound to come if no serious measures are taken in time (Nazer et al. 2008).

Pilot projects can play a significant role in awareness raising. Areas without water supply or sanitation system and very low water consumption can be fertile grounds for implementing pilot projects. In this context Matsui et al. (2001) stated that the existing sanitation systems in the developed countries are not suited to a world where environmental protection is a priority. Developing countries, like Palestine, have an opportunity to skip the phase of water wasting sanitary facilities and to move directly into the implementation of water conscious sanitary equipment.

The introduction of these water management options should, in the very near future, be oriented towards a situation in which each single- and multi-family housing property is largely independent in terms of water and sanitation systems. Each property should have its own water resource (RWHS) and its own used-water treatment system (gray-water treatment system in combination with a dry toilet). This can be achieved by adapting building codes accordingly. However, this may not be 
possible in some places where rainwater harvesting does not yield sufficient water. In such places water, made available by reduced demand, can be supplied from other resources.

\section{Conclusions}

The objective of this study was to evaluate the environmental, financial and social impacts of potential domestic water management options using life cycle impact assessment (LCIA) and to propose a water use scheme for the house of tomorrow, in line with the use-treat-reuse approach. The main findings of this study were that by introducing a combination of water management options in the domestic area, a substantial decrease in water consumption of up to $50 \%$ could be achieved, thereby reducing the pressure on the scarce water resources. This reduction can be achieved because the water was used more than once and not at the expense of water use purposes; thus reducing the use of groundwater. Environmental and financial impacts can be reduced similarly; the annual environmental impact of the in-house water use can be reduced by some $8 \%$ when using low-flow shower heads, and up to $38 \%$ when using rainwater harvesting systems. Some of the options investigated were found to be financially attractive such as faucet aerators, low-flow shower heads and dual flush toilets. However, others (rainwater harvesting, gray-water reuse systems and dry toilets) were found unattractive because of the high investment needed. However, the social and health benefits may justify these investments. In the social context, it was found that introducing such options can improve the quality of life of those not having sufficient water. It was concluded that, theoretically, the house of tomorrow can be largely independent in terms of water and sanitation. It was also concluded that there is a popular willingness to take part in water conservation in the domestic sector in the West Bank. The strongest driving force for using water conservation measures is the awareness that water is a scarce resource. Education and awareness campaigns in the context of water management with a focus on nontraditional options, such as dry toilets, are key to achieving sustainable water use.

Acknowledgements Thanks are extended to all organizations and individuals who have participated in the workshops or helped in filling out the questionnaires, out of which the data presented in this study, were obtained. The participation of school students in measuring indoor water consumption is highly appreciated. Thanks are due to all schools (staff and students) who participated in this study. A special thank you to Sima Kuhail for her dedicated help in implementing the workshops related to this study and processing the data collected from these workshops, Layana Nazer and Lina Afifi for their help in collecting data. Thanks are extended to Patricia Sellick for reviewing the paper for English.

Open Access This article is distributed under the terms of the Creative Commons Attribution Noncommercial License which permits any noncommercial use, distribution, and reproduction in any medium, provided the original author(s) and source are credited.

\section{References}

Baguma D, Loiskandl W, Jung H (2010) Water management, rainwater harvesting and predictive variables in rural households. Water Resour Manage, published online 18 February 2010. doi:10.1007/s11269-010-9609-9 
Bandyopadhyay S (2005) Gross national happiness and beyond: a micro welfare economics approach. Paper presented in the Second International Conference on Gross National Happiness, St. Francis Xavier University, Antigonish, Nova Scotia, Canada, June 2005. http://www. gpiatlantic.org/conference/papers. Accessed Nov 2008

Barrios R, Siebel M, Helm A, Bosklopper K, Gijzen H (2008) Environmental and financial life cycle impact assessment of two plants of Amsterdam water supply. J Clean Prod 16(4):471-476

Bennett D (1995) Graywater, an option for household water reuse. Home Energy Magazine online. http://homeenergy.org/archive. Accessed Jan 2004

Blank L, Tarquin A (2005) Engineering economy, 6th edn. International edition, McGrawHill

Chase W, Bown F (1986) General statistics. John Wiley and Sons, Inc., New York

CIA (2009) CIA-The world fact book, West Bank. http://www.cia.gov//library/publications/ the_world_factbook/geor/.html. Accessed March 2009

Cunningham WP, Saigo BW (1999) Environmental science a global concern, 5th edn. McGraw-Hill Companies, USA

Environmental Protection Agency (EPA) (1995) Cleaner water through conservation. US Environmental Protection Agency. http://www.epa.gov/waterhome. Accessed Feb 2004

European Environmental Agency (EEA) (1997) Life cycle assessment, a guide to approaches, experiences and information sources. http://reports.eea.europa.eu/GH-07-97-595-EN-C/en/ Issue \%20report\%20No\%206.pdf. Accessed Oct 2007

Ezechieli E (2003) Beyond sustainable development: education for gross national happiness in bhutan, monograph of the degree of master of arts, Stanford University. http://suse-ice.stanford. edu/monograghs/Ezechieli.pdf. Accessed Nov 2008

Gijzen HJ (1998) Sustainable wastewater management via re-use-turning waste into wealth. In: Garcia M, Gijzen HJ, Galvis G (eds) Proc. AGUA_water and sustainability, 1-3 June 1998, Cali, Colombia, pp 211-225

Gijzen HJ (2001) Aerobes, anaerobes and phototrophs-a winning team for wastewater management. Water Sci Technol 44(8):123-132

Goedkoop M, Effting S, Collignon M (2000) The Eco-indicator 99. A damage oriented method for life cycle impact assessment, manual for designers, 2nd edn. Pre consultants, Amersfroot. www.pre.nl. Accessed Jun 2008

Hauschild M, Jeswiet J, Alting L (2005) From life cycle assessment to sustainable production: status and perspectives. Annals CIRP 54(2):535-555

Hofstetter P, Madjar M, Ozawa T (2006) Happiness and sustainable consumption: psychological and physical rebound effects at work in a tool for sustainable design. Int J LCA 11(1):105-115

Hutton G, Bartram J (2008) Global costs of attaining the millennium development goal for water supply and sanitation. Bull WHO 86(1):13-19

Hutton G, Haller L, Bartram J (2007) Economic and health effects of increasing coverage of low cost household drinking-water supply and sanitation interventions to countries off-track to meet MDG target 10. Public Health and the Environment, World Health Organization (WHO), Geneva

Ibrahim MB (2009) Rainwater harvesting for urban areas: a success story from Gadarif City in Central Sudan. Water Resour Manag 23:2727-2736. doi:10.1007/s11269-009-9405-6

Jerusalem Water Undertaking (JWU) (2007) Water prices, rates and tariffs, Ramallah, Palestine, http://www.jwu.org. Accessed Jun 2007

Krishna HJ (2005) The Texas manual on rainwater harvesting, 3rd edn. Texas Water Development Board, Austen. http://www.twdb.state.Tx.us/publications/reports/RainwaterHarvestingManual3rdedition.pdf. Accessed Jun 2007

Layard R (2005) Happiness, lessons from a new science. Penguin Books, London

Mahmoud N, Amarneh N, Al-sa'ed R, Zeeman G, Gijzen H, Lettinga G (2003) Sewage characterization as a tool for the application of anaerobic treatment in Palestine. Environ Pollut 126:115-122

Matsui S, Henze M, Ho G, Otterpohl R (2001) Emerging paradigms in water supply and sanitation. In: Frontiers in urban water management: dead lock or hope. IWA publishing and UNESCO, UK

Mayer PW, De Oreo WB, Towler E, Lewis DM (2003) Residential indoor water consumption study: evaluation of high efficiency indoor plumbing fixture retrofits in single-family homes in the East Bay Municipal Utility District Service Area. Prepared for East Bay Municipal Utility District and the US Environmental Protection Agency (EPA), Aquacraft, Inc. Water Engineering and Management, Boulder. www.aquacraft.com. Accessed Jul 2007

Mayer PW, De Oreo WB, Towler E, Martien L, Lewis DM (2004) Tampa water department residential water consumption study: the impacts of high efficiency plumbing fixture retrofits 
in single-family homes. Prepared for Tampa Water Department and the US Environmental Protection Agency (EPA), Aquacraft, Inc. Water Engineering and Management, Boulder. www.aquacraft.com. Accessed Jul 2007

Ministry of Planning and International Cooperation (MOPIC) (1998) Regional plan for the West Bank governorates, water and wastewater existing situation, 1st edn. Ministry of Planning and International Cooperation, Palestine

Nazer DW (2009) From water scarcity to sustainable water use in the West Bank, Palestine. Ph.D. thesis, Taylor and Francis Group

Nazer DW, Al-Sa'ed RM, Siebel MA (2006) Reducing the environmental impact of the unhairingliming process in the leather tanning industry. J Clean Prod 14(1):65-74

Nazer DW, Siebel MA, Mimi Z, Van der Zaag P (2007) Reducing domestic water consumption as a tool to raise water awareness in the West Bank, Palestine. Paper presented in the 13th International Sustainable Development Research Conference, Vasteras, Sweden, 10-12 June 2007

Nazer DW, Siebel MA, Mimi Z, Van der Zaag P, Gijzen HJ (2008) Water footprint of the Palestinians in the West Bank, Palestine. J Am Water Resour Assoc (JAWRA) 44(2):449-458

PCBS (Palestinian Central Bureau of Statistics) (2007) The Palestinian expenditure and consumption survey 2006, levels of living in the Palestinian territory. The final report (January 2006-January 2007), Palestinian Central Bureau of Statistics, Palestine

PECDAR (2001) Palestinian water strategic planning study. Palestinian Economic Council for Development and Reconstruction

Philippatos GC, Sihler WW (1991) Financial management text and cases, 2nd edn. Allyn and Bacon, Massachusetts

PLANETARK (2007) Graywater: the basics. Graywater fact sheet series. http://www.planetark.com/ products/PAGreyWaterInfo.pdf. Accessed Jun 2008

Rosegrant MW, Cai X, Cline SA (2002) Global water outlook to 2025. Averting an impeding crisis, food policy report. A 2020 vision for food, agriculture, and the environment initiative. International Food Policy Research Institute (IFPRI) and International Water Management Institute (IWMI), Colombo

Siebel MA, Gijzen HJ (2002) Application of cleaner production concepts in urban water management. In: Workshops Alcue-Sustainable development and urbanization: from knowledge to action. Science \& Technology, vol 3

Siebel MA, Chang CT, Gijzen HJ, Rotter VS (2007) Life cycle impact assessment-a case study of solid waste collection. In: Proceedings of the eleventh international waste management and landfill symposium. S. Margherita di Pula, Cagliari, Italy; 1-5 October by CISA, Environmental Sanitary Engineering Centre, Italy

Udo de Haes H, Heijungs R, Suh S, Huppes G (2004) Three strategies to overcome the limitations of life-cycle assessment. J Ind Ecol 8(3):19-32

UNEP (United Nations Environment Program) (1996) Life cycle assessment: what it is and how to do it?, 1st edn. United Nations Publications, Paris

UNEP (United Nations Environment Program) (1999) International cleaner production information. Paris, France

Van der Zaag P (2000) Estimating storage requirement for rainwater harvested from roofs. Paper Presented at the 4th Biennial Congress of the African Division of the International Association of Hydraulic Research, Windhoek, Namibia

WCED (World Commission on Environment and Development) (1987) Our common future. Oxford University Press, United Kingdom

Zhang Y, Grant A, Sharma A, Chen D, Chen L (2010) Alternative water resources for rural residential development in western Australia. Water Resour Manag 24:25-36. doi:10.1007/s11269009-9435-0 